\title{
Clinical Relevance of Pre-Existing and Treatment-Induced Anti-Poly(Ethylene Glycol) Antibodies
}

\author{
Helena Freire Haddad ${ }^{1,2}$. Jacqueline A. Burke ${ }^{1,2}$. Evan A. Scott ${ }^{1,2,3,4,5,6,7}$. Guillermo A. Ameer ${ }^{1,2,3,4,5,8,9}$ (ID
}

Received: 14 November 2020 / Revised: 18 January 2021 / Accepted: 28 January 2021 / Published online: 25 March 2021

(C) The Regenerative Engineering Society 2021

\begin{abstract}
Poly(ethylene glycol) (PEG) is a nontoxic, hydrophilic polymer that is often covalently attached to proteins, drugs, tissues, or materials; a procedure commonly referred to as PEGylation. PEGylation improves solubility, circulation time, and reduces immunogenicity of therapeutic molecules. Currently, there are 21 PEGylated drugs approved by the Food and Drug Administration (FDA), and more in the developmental stage. In addition to the polymer's applications in the clinic, PEG is widely used as a solvent and emulsifying agent in the formulation of cosmetics, cleaning, and personal care products. Due to the ubiquitous presence of the polymer in everyday products, patients can develop antibodies against PEG ( $\alpha$ PEG Abs) that can be problematic when a PEGylated drug is administered. These $\alpha$ PEG Abs can provoke hypersensitivity reactions, accelerated drug clearance, and decreased therapeutic efficacy. Herein, we review how the prevalence of PEG in everyday products has induced $\alpha$ PEG Abs within the general public as well as the effect of these Abs on the performance of PEGylated therapeutics. We will focus on clinical manifestations following the administration of PEGylated drugs.
\end{abstract}

\section{Lay Summary}

Poly(ethylene glycol) (PEG) is a polymer found in products including cosmetics, personal care products, cleaning agents, medicine, and food. Due to the prevalence of PEG, people can develop antibodies ( $\alpha$ PEG Abs) against the polymer, which recognize PEG as foreign. Of note, PEG is frequently incorporated into drug formulations to improve therapeutic efficacy. Complications can arise when a patient receiving a PEGylated drug has previously developed $\alpha$ PEG Abs from interactions with PEG in everyday products. The presence of high concentrations of $\alpha$ PEG Abs in blood can result in decreased treatment efficacy and allergic reactions to a wide range of therapeutics.

Keywords Poly(ethylene glycol) $\cdot$ PEGylation $\cdot$ Anti-PEG antibodies $\cdot$ PEG immunogenicity $\cdot$ Doxil

Helena Freire Haddad and Jacqueline A. Burke contributed equally to this work.

Evan A. Scott

evan.scott@northwestern.edu

Guillermo A. Ameer

g-ameer@northwestern.edu

1 Department of Biomedical Engineering, Northwestern University, 2145 Sheridan Road 2145 Sheridan Rd. E310, Evanston, IL 60208, USA

2 Center for Advanced Regenerative Engineering, Northwestern University, 2145 Sheridan Road, E311, Evanston, IL 60208, USA

3 Interdisciplinary Biological Sciences, Northwestern University, 2205 Tech Drive, Evanston, IL 60208, USA

4 Chemistry of Life Processes Institute, Northwestern University, 2179 Campus Drive, Evanston, IL 60208, USA
5 Simpson Querrey Institute, Northwestern University, 303 E. Superior Street, 11th Floor, Chicago, IL 60611, USA

6 Comprehensive Transplant Center, Feinberg School of Medicine, Northwestern University, 676 N. St. Clair Street, 19th Floor, Chicago, IL 60611, USA

7 Robert H. Lurie Comprehensive Cancer Center, Northwestern University, 676 N. St. Clair Street, Suite 1200, Chicago, IL 60611, USA

8 Department of Surgery, Feinberg School of Medicine, Northwestern University, 676 N. St. Clair Street, Suite 2320, Chicago, IL 60611, USA

9 International Institute for Nanotechnology, Northwestern University, 2145 Sheridan Road, K111, Evanston, IL 60208, USA 


\section{Prevalence and Properties of Poly(Ethylene Glycol)}

Poly(ethylene glycol) (PEG) is a polymer composed of ethylene oxide monomers that have been engineered into a diverse range of chain conformations and structures. These architectures consist of both linear and branched polymer chains in molecular weights ranging from $\sim 550$ to $>8,000,000 \mathrm{Da}$ (Fig. 1) [1-3]. Over the past 40 years, PEG has shown great potential to overcome rapid clearance, low solubility, and high immunogenicity associated with controlled and therapeutic delivery of small molecules and biologics in both commercial and academic settings [4-7]. PEG chains can be covalently attached to drugs or the surfaces of materials in a technique called PEGylation (Fig. 1c) $[4,5]$. PEG can also serve as an emulsifying agent in drug formulations $[4,5]$.

Following dense surface PEGylation, a steric shield of PEG chains can form wherein each PEG monomer subunit associates with two to three water molecules, inhibiting nonspecific protein interactions to minimize immunogenic recognition by neutralizing antibodies and the degradative action of proteolytic enzymes [5, 8].

Moreover, PEGylation reduces nonspecific clearance via the mononuclear phagocytic system by inhibiting receptormediated endocytosis and scavenging by phagocytic myeloid

a<smiles>CCCCOCC(C)O</smiles>

Functionalized PEG<smiles>[2H]C([2H])(C)CO[CH]</smiles>

Linear MPEG<smiles>CC(C)OCCC(C)(C)O</smiles>

$$
\text { Bifunctional PEG }
$$

Functionalized Branched PEG<smiles>[Y]C(NCC(=O)OC#[R][H])C(=O)O</smiles>

and endothelial cells $[8,9]$. In addition to reducing immunogenicity, PEGylation also increases the circulation time of small molecules by limiting clearance by the renal system and phagocytic innate immune cells of the mononuclear phagocyte system (MPS). Glomerular filtration depends heavily on the size and molecular weight of a particle due to the structure and permeability of the glomerulus [10, 11]. PEGylation increases the hydrodynamic diameter (HD) and molecular weight of the PEGylated moiety, thereby limiting renal clearance and increasing circulation time (Fig. 2) [4, 7]. Particles with an HD larger than $8 \mathrm{~nm}$ experience significantly reduced filtration and elimination by the kidneys [10].

Due to the unique properties conferred by $P E G$, PEGylation has become the go-to method of enhancing the delivery of therapeutic molecules [12]. As of 2020, there were 21 PEGylated drugs approved by the FDA, and over 20 others in active clinical trials $[13,14]$. These drugs include PEGylated enzymes, proteins, and liposomes, which are used in the treatment of numerous disorders such as infectious disease, cancer, autoimmune diseases, and genetic disorders [13-16]. Approved therapeutics currently contain PEG molecular weights ranging from less than $1 \mathrm{kDa}$ to $40 \mathrm{kDa}$ (Table 1) $[13,14]$.

In addition to the extensive application of PEG in the pharmaceutical industry, the polymer is also used as a solvent and<smiles>CC(C)[NH3+]</smiles>

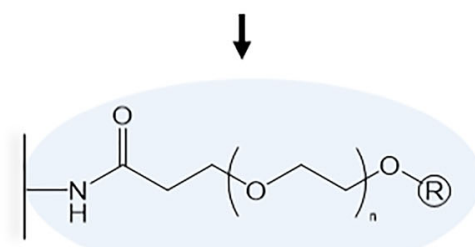

d PEGylated liposome: mPEG-DSPE

b i<smiles>O=C1C=CC(=O)N1C=C=[Fe]</smiles>

iii<smiles>C=CS(=O)(=O)[Se]=[Fe]</smiles>

ii<smiles>O=C(CCC(=O)ON1C(=O)CCC1=O)O[Ga]=[Fe]</smiles>

iv<smiles>O=C(ON1C(=O)CCC1=O)[Se]=[Fe]</smiles>

Fig. 1 Chemical structures of PEG. a Commonly used PEG architectures and functionalization. $\mathrm{R}$ represents a functional group. $\mathbf{b}$ Common PEG R groups: i malemide; ii succinimidyl succinate; iii vinyl sulfone; iv Nhydroxysuccinimide. $\mathbf{c}$ Click chemistry reaction between a bifunctional
PEG chain and amine group on a protein coated surface. d PEGylated lipid, mPEG-DSPE, used in the formulation of PEGylated liposomal drugs such as Doxil ${ }^{\circledR}$ 
a PEGylated Therapeutic Without aPEG Abs

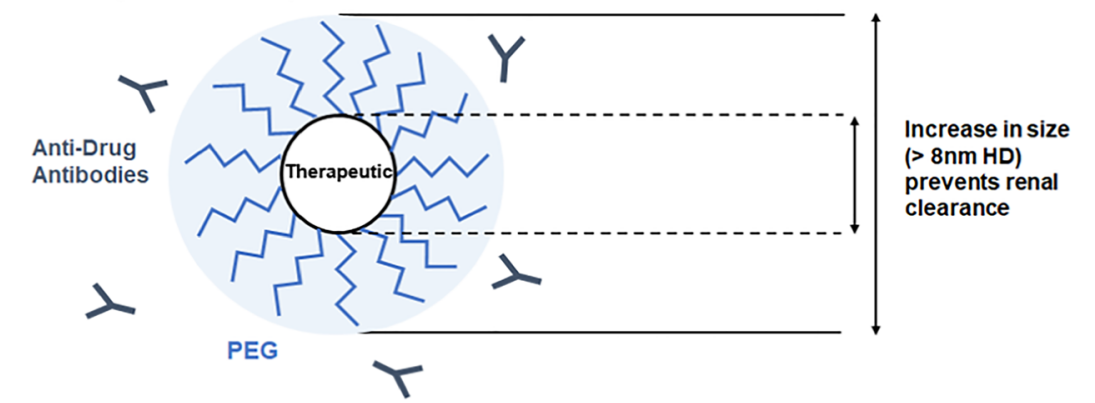

b Non-PEGylated Therapeutic

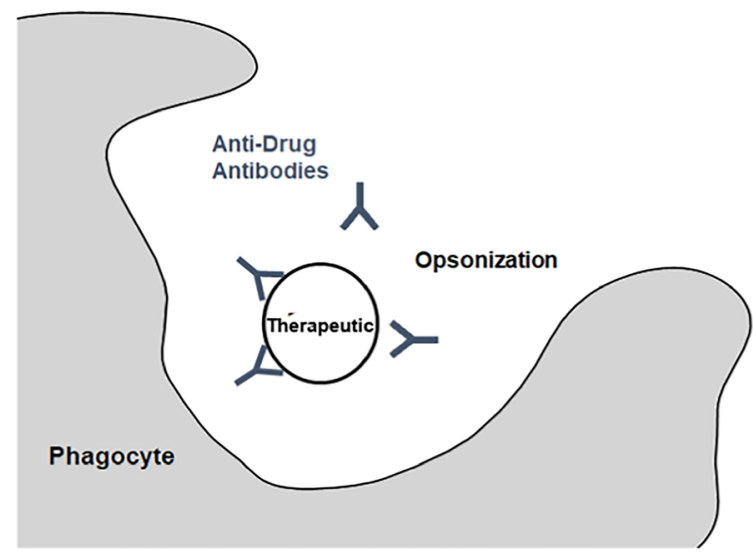

Fig. 2 Properties of PEGylated therapeutics in the absence and presence of $\alpha$ PEG Abs a PEG associates with water molecules to create a shield around a PEGylated therapeutic, protecting the drug from immunogenic recognition by anti-therapeutic antibodies. Additionally, PEGylation increases the $\mathrm{HD}$ of a therapeutic, preventing renal clearance. $\mathbf{b}$ The

emulsifying agent in consumer products $[17,18]$. PEG can be found in everyday products such as shampoo, moisturizers, makeup, and soap [2, 17]. In 1992, product formulation data reported to the FDA showed that 7 structures of PEG, varying in molecular weight, polymer architecture, and functionalization, could be found in 262 different commercially available cosmetic formulations [2]. By 2015, the variations of PEG found in cosmetic products had increased drastically to over 340 structures [17]. The prevalence of PEG in consumer products has increased in the past four decades, with a growing variety of chain sizes, structures, and functional groups, and this trend is likely to continue $[2,17]$.

PEG has been implemented so widely in the cosmetic and pharmaceutical industry partially due to its perceived inert nature [7]. However, in 1983, it was first reported that $\alpha$ PEG Abs could be observed in rabbits following immunization with PEGylated ovalbumin [19]. The antigen was emulsified using Freund's complete adjuvant, which is known to amplify the antibody response [19]. One year later, levels of pre-existing $\alpha$ PEG Abs were first detected in blood donors without previous exposure to PEGylated therapeutics [20]. $\alpha$ PEG Abs detected in humans have been hypothesized to develop due to the repeated exposure to PEG-containing c PEGylated Therapeutic With aPEG Abs

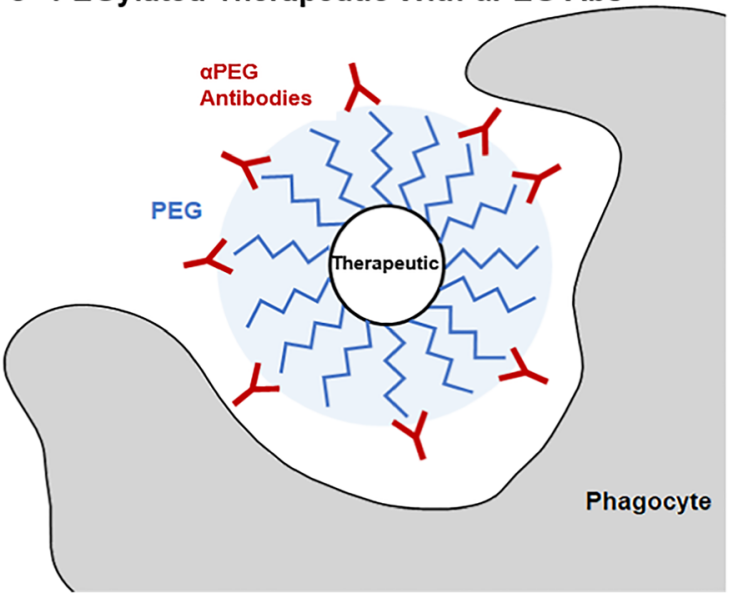

same therapeutic, if non-PEGylated, can be opsonized by antitherapeutic Abs, and later phagocytosed, in addition to being cleared by the kidneys. $\mathbf{c}$ In the presence of $\alpha$ PEG Abs, the PEGylated therapeutic can be opsonized by $\alpha$ PEG Abs and phagocytosed

products [21]. Both $\alpha \mathrm{PEG}$ immunoglobulin $\mathrm{M}(\operatorname{IgM})$ and $\mathrm{G}$ (IgG) have been observed in healthy blood donors [21]. IgM is associated with the primary immune response, appearing upon the first exposure to an antigen, while IgG is usually associated with a secondary antigen exposure [22]. In the presence of pre-existing $\alpha$ PEG Abs, patients receiving treatment with a PEGylated drug can experience accelerated blood clearance, changes in pharmacokinetic after multiple doses, decreased therapeutic function due to decreased therapeutic circulation time, and hypersensitivity reactions [23-25].

Since the 1990 approval of the first PEGylated drug Adagen $\AA$, an enzyme replacement therapy for the treatment of severe combined immunodeficiency disease, there has been a considerable increase in the pervasiveness of PEG in both the formulation of personal care products and FDA approved PEGylated therapeutics (Fig. 3) [14]. Physicians and researchers have been investigating how $\alpha \mathrm{PEG}$ Abs emerge and interfere with therapeutics. Given the increasing prevalence of PEG in the clinic and on consumer's shelves, further investigation is required to fully assess the safety and efficacy of PEGylated drugs. Reactions to PEGylated drugs can cause life-threatening consequences to patients [23]. Numerous reports of pre-existing and drug-induced $\alpha \mathrm{PEG}$ Abs causing 
Table 1 PEGylated drugs approved by the FDA. Adapted from [13, 14]

\begin{tabular}{|c|c|c|c|c|c|c|}
\hline $\begin{array}{l}\text { Brand } \\
\text { name }\end{array}$ & Generic name & Indication & $\begin{array}{l}\text { PEGylated } \\
\text { molecule }\end{array}$ & $\begin{array}{l}\text { PEG size } \\
(\mathrm{kDa})\end{array}$ & $\begin{array}{l}\text { \# PEG } \\
\text { chains }\end{array}$ & $\begin{array}{l}\text { Year } \\
\text { approved }\end{array}$ \\
\hline Adagen & Pegademase bovine & Severe combined immunodeficiency disease & Enzyme & 5 & $11-17$ & 1990 \\
\hline Oncaspar & Pegasparginase & Acute lymphoblastic leukemia & Enzyme & 5 & $69-82$ & 1994 \\
\hline Doxil & $\begin{array}{l}\text { Doxorubicin hydrochloride } \\
\text { liposome }\end{array}$ & $\begin{array}{l}\text { Ovarian cancer, AIDS-related Kaposi's Sarcoma, } \\
\text { multiple myeloma }\end{array}$ & Liposome & 2 & $\mathrm{n} / \mathrm{a}$ & 1995 \\
\hline Onivyde & Irinotecan liposome & Metastatic adenocarcinoma of the pancreas & Liposome & 2 & $\mathrm{n} / \mathrm{a}$ & 1996 \\
\hline Pegasys & Peginterferon alfa- $2 a$ & Hepatitis B, C chronic & Protein & 40 & 1 & 2001 \\
\hline PegIntron & Peginterferon alfa- $2 b$ & Hepatitis $\mathrm{C}$, chronic & Protein & 12 & 1 & 2001 \\
\hline Neulasta & Pegfilgrastim & $\begin{array}{l}\text { Neutropenia, hematopoietic subsyndrome of acute } \\
\text { radiation syndrome }\end{array}$ & Protein & 20 & 1 & 2002 \\
\hline Somavert & Pegvisomant & Acromegaly & Protein & 5 & $4-6$ & 2003 \\
\hline Macugen & Pegaptanib & Neovascular age-related macular degeneration & Aptamer & 20 & 2 & 2004 \\
\hline Mircera & mPEG-epoetin beta & Anemia associated with chronic kidney disease & Protein & 30 & 1 & 2007 \\
\hline Cimzia & Certolizumab pegol & $\begin{array}{l}\text { Crohn's disease, rheumatoid arthritis, psoriatic arthritis, } \\
\text { ankylosing spondylitis }\end{array}$ & $\begin{array}{l}\text { FAB } \\
\text { fragment }\end{array}$ & 40 & 1 & 2008 \\
\hline Krystexxa & Pegloticase & Gout & Enzyme & 10 & 36 & 2010 \\
\hline Sylatron & Peginterferon alfa- $2 b$ & Melanoma & Protein & 12 & 1 & 2011 \\
\hline Omontys & Peginesatide & Anemia associated with chronic kidney disease & Peptide & 40 & 1 & 2012 \\
\hline Movanik & Naloxegol & Opioid-induced constipation & $\begin{array}{l}\text { Small } \\
\text { molecule }\end{array}$ & $<1$ & 1 & 2014 \\
\hline Plegridy & Peginterferon beta- $1 \mathrm{a}$ & Multiple sclerosis & Protein & 20 & 1 & 2014 \\
\hline Adynovate & $\begin{array}{l}\text { Antihemophilic factor, } \\
\text { PEGylated }\end{array}$ & Hemophilia A & Protein & 20 & 1 or more & 2015 \\
\hline Rebinyn & $\begin{array}{l}\text { Coagulation factor IX, } \\
\text { glyco PEGylated }\end{array}$ & Hemophilia B & Protein & 40 & 1 & 2017 \\
\hline Asparlas & Calaspargase pegol & Acute lymphoblastic leukemia & Enzyme & 5 & $31-39$ & 2018 \\
\hline Palynziq & Pegvaliase & Phenylketonuria & Enzyme & 20 & 9 & 2018 \\
\hline Revcovi & Elapegademase & $\begin{array}{l}\text { Adenosine deaminase severe combined } \\
\text { immunodeficiency }\end{array}$ & Enzyme & 5.6 & 13 & 2018 \\
\hline
\end{tabular}

adverse reactions against PEGylated drugs in the lab and in the clinic have emerged in recent years [23, 25-27]. Adverse reactions caused by $\alpha$ PEG Abs can lead to the early termination of clinical trials, posing a huge financial burden to drug developers [27]. It has been estimated that the cost per patient in a phase 3 clinical trial is approximately $\$ 42,000$ [28]. Therefore, a failed clinical trial would result in the loss of millions, if not billions of dollars. This problem highlights a pressing need for testing PEGylated drugs in animal models with relevant blood concentrations of $\alpha$ PEG Abs before trials in human patients.

\section{Immunological Mechanisms of aPEG Ab Induction}

The immune mechanism that leads to the production of $\alpha \mathrm{PEG}$ Abs must be understood. Both T cell-independent (TI) and T cell-dependent (TD) mechanisms have been proposed for the induction of $\alpha$ PEG Abs. TI $\alpha$ PEG Ab induction occurs when the antigen crosslinks with receptors on IgM (natural effector) memory B cells. These cells are commonly found in the marginal zone of the spleen in rodents [29]. As a result, these cells secrete high concentrations of IgM. Low concentrations of

\begin{tabular}{|c|c|c|}
\hline $\begin{array}{l}\text { 1984: Richter et al. } \\
\text { detect aPEG Abs } \\
\text { in } 0.3 \% \text { of healthy } \\
\text { donors }\end{array}$ & $\begin{array}{lc}\text { 1990: First } & \text { 1995: First } \\
\text { PEGylated drug } & \text { nanodrug } \\
\text { approved by the } & \text { approved by the } \\
\text { FDA (Adagen } 囚 \text { ) } & \text { FDA (Doxil囚) }\end{array}$ & $\begin{array}{l}\text { 2016: Yang et al. } \\
\text { detect aPEG Abs } \\
\text { in } 72 \% \text { oh } \\
\text { healthy donors } \\
\text { (mean: } 52 \mathrm{ng} / \mathrm{ml} \text { ) }\end{array}$ \\
\hline & $\begin{array}{l}\text { 1992: } 7 \text { distinct } \\
\text { PEG structures } \\
\text { present in } \\
\text { consumer } \\
\text { products }\end{array}$ & $\begin{array}{l}\text { 2015: } 340 \text { distinct } \\
\text { PEG structures } \\
\text { present in } \\
\text { consumer products }\end{array}$ \\
\hline
\end{tabular}

Fig. 3 Timeline of the prevalence of $\alpha$ PEG Abs (red), PEGylated drugs (black), and PEG in consumer products (blue) 
IgG have also been observed in parallel with IgM. No class switching is observed. Abs produced via the TI pathway have a weaker affinity for PEG as compared to their TD counterparts. TI induction of $\alpha$ PEG Abs has been associated with the injection of PEGylated nanoparticles, such as PEGylated liposomes (Table 2) [29-34].

Work by Ishida et al. has been transformative in the understanding of the TI mechanism [29-33]. Ishida et al. demonstrated that the spleen plays a large role in the induction of $\alpha$ PEG IgM with PEGylated liposomes [35]. Upon the first exposure to PEGylated liposomes, $\alpha$ PEG IgM is induced and secreted by the spleen. When a second injection is administered, IgM binds selectively to PEG, triggering the complement system. The liposomes are then opsonized and phagocytosed by Kupffer cells in the liver. This leads to increased particle accumulation in the liver and a decrease in circulation time for the second dose of liposomes, associated with the accelerated blood clearance $(\mathrm{ABC})$ phenomenon. Ishida et al. surgically removed the spleens of rats at different timepoints prior to a first injection with PEGylated liposomes. Animals that had been splenectomized showed reduced levels of $\alpha$ PEG IgM after first exposure to PEGylated liposomes. After a second injection, the animals did not present the drastic decrease in circulation time nor an increase in liver accumulation of liposomes associated with the $\mathrm{ABC}$ phenomenon. Additionally, serum from splenectomized rats showed diminished complement activation upon exposure to PEGylated liposomes in vitro.

Ishida et al. employed immunodeficient athymic mice to verify TI $\alpha$ PEG Ab induction [32]. These mice were injected with PEGylated liposomes, and 10 days after the injection $\alpha$ PEG IgM and IgG levels were assessed. A significant IgM titer was detected in the absence of $\mathrm{T}$ cells, and the depletion of marginal zone lymphocytes in

Table 2 Comparison of T cell independent and dependent mechanisms of $\alpha$ PEG Ab induction [29, 34, 36-38]

\begin{tabular}{ccc}
\hline & T-Cell Independent & T-Cell Dependent \\
\hline Known Inducers & PEGylated Nanoparticles & PEGylated Proteins
\end{tabular}

Antigen Presentation

Antigen crosslinks with IgM (natural effector) memory B cells

Primary Response

Secondary Response

Avidity of Resulting $\alpha$ PEG Abs for PEG
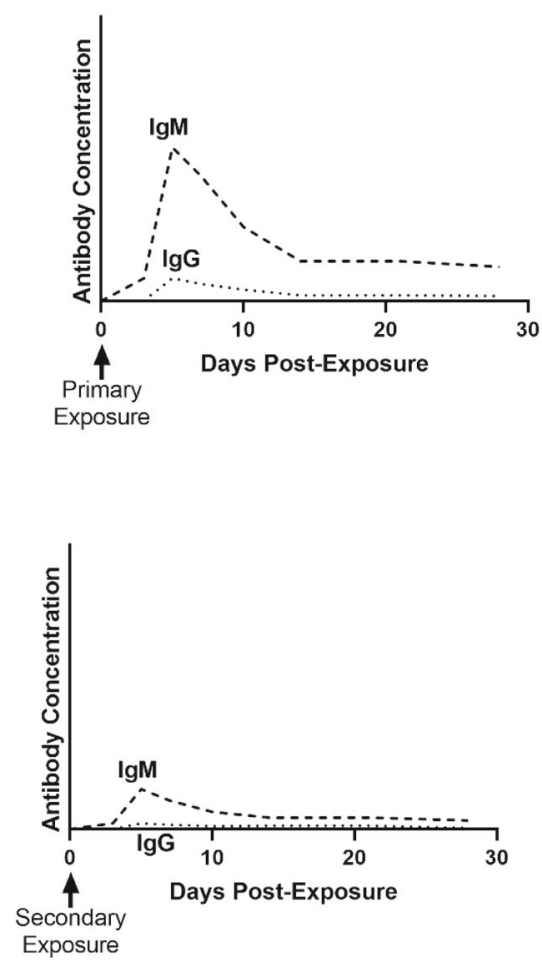

Low
Presentation of peptides to helper T cells by antigenspecific B cells
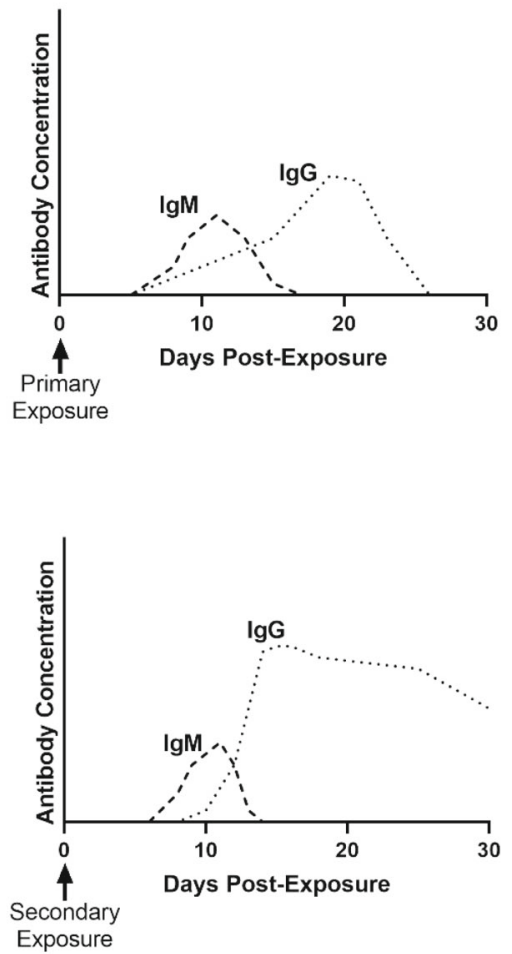

High 
the spleen, which are presumed to be B cells, significantly suppressed $\alpha$ PEG IgM induction. The authors propose that the induction of $\alpha$ PEG IgM occurs by a TI mechanism, in which PEG activates marginal B cells directly. The same mechanism has been observed in immune reactions against other highly repetitive structures, such as polysaccharides [39]. The time course of $\alpha$ PEG Ab IgM and $\mathrm{IgG}$ titers induced by the TI mechanism have been assessed by Kozma et al. in a larger porcine animal model. Pigs injected intravenously with PEGylated liposomes showed a rise in IgM titers within 5 days, peaking around 10 days. IgG titers paralleled IgM titers in time course but were significantly lower in concentration. A secondary response did not occur with repeated injections [40].

In contrast, $T$ cell-dependent (TD) mechanisms have been observed when the PEGylated moiety is an immunogenic protein $[29,41]$. The induction of Abs is triggered by the presentation of peptides to helper T cells by B cells. The resulting Abs have a high affinity for PEG. The Ab response is characterized by an initial peak in IgM, followed by class switching, and then a larger peak in IgG. The IgG peak is always greater in concentration than the IgG peak. Unlike for TI mechanisms, TD mechanisms are characterized by a much stronger secondary response relative to the primary response (Table 2) $[29,34$, 36-38]. Sherman et al. and Saifer et al. demonstrated the TD mechanism in rabbits. Injection of PEGylated proteins given with or followed by Freund's adjuvant led to the production of $\mathrm{IgG}$. These researchers showed that generally $\mathrm{Ab}$ production occurred despite variations in protein type (human interferonalpha, porcine uricase, or human serum albumin), PEG functionalization (methoxy-, hydroxy-, and t-BuO-), and molecular weight. Thus, validating the TD mechanism.

In a study by Mima et al., $\alpha$ PEG IgM was induced in a dosedependent manner in mice injected with PEGylated ovalbumin (PEG-OVA) [29]. However, immunodeficient mice did not develop $\alpha$ PEG IgM upon receiving the same PEG-OVA injection, indicating a TD mechanism. Another study investigated the $\alpha$ PEG IgM response upon administration of Pegfilgrastim, the PEGylated form of recombinant human granulocyte colony-stimulating factor [41]. Splenectomized mice did not develop $\alpha$ PEG IgM, indicating that the spleen plays a role in $\mathrm{Ab}$ induction. This is consistent with previous observations of the $\mathrm{Ab}$ response to PEGylated liposomes [35]. However, similar to PEG-OVA [29], the $\alpha$ PEG IgM response was significantly lower in immunodeficient mice [41]. In animals treated with cyclophosphamide, which depletes mice of splenic Bcells, lower $\alpha$ PEG IgM levels were also observed [41].

\section{Pre-Existing aPEG Abs in the Population}

In 1984 , the first attempt to study the prevalence of $\alpha$ PEG Abs was made by Richter et al. [20]. Serum samples from 453 healthy volunteers were obtained from blood banks in Japan, Germany, and Italy, as well as from 92 patients allergic to ragweed and honey bee venom [20]. Samples were analyzed using a passive hemagglutination assay, in which red blood cells (RBCs) coated with $6 \mathrm{kDa}$ methoxy-PEG (mPEG) were incubated with serial dilutions of donor sera [20]. If the blood agglutinated or clumped, the presence of Abs against PEG was confirmed. Due to the semi-quantitative nature of this assay, it is not possible to state the levels of detection in comparison to other quantitative methods. Positive $\alpha$ PEG Ab titers, predominantly $\operatorname{IgM}$, were detected in $0.2 \%$ of healthy patients, and in $3.3 \%$ of patients with untreated allergies [20]. The increased prevalence of pre-existing $\alpha \mathrm{PEG} A b$ in patients with allergies in comparison to healthy patients was not discussed, and the reason for this difference remains unknown [20]. Patients with allergies were treated with PEGylated allergens for hyposensitization therapy for one year, and $50 \%$ of the patients had positive $\alpha \mathrm{PEG} \mathrm{Ab}$ titers at the end of the treatment [20]. One year after the end of the treatment, positive titers were detected in only $28.5 \%$ of the patients. Despite the notable increase in detected $\alpha$ PEG Ab after treatment with PEGylated allergens, and the persistence of $\alpha$ PEG Abs in over half of the patients, Richter et al. deemed the increased $\mathrm{Ab}$ response in patients with allergies to not be of clinical significance and claimed it would not affect treatment with PEGylated allergens. This conclusion ignored the risk of potentially anaphylaxis-inducing hyposensitization therapies and delayed research concerning $\alpha$ PEG Abs, as many doubted their importance in the clinic [42].

In 2016, Yang et al. analyzed 377 contemporary serum samples, as well as 79 historical serum samples from the 1970s to 1990s [21]. Using a quantitative, competitive enzyme-linked immunosorbent assay (ELISA) with detection limits ranging from 2 to $15 \mathrm{ng} / \mathrm{ml}, 72 \%$ of contemporary samples were found to have detectable levels of $\alpha$ PEG Abs. The geometric mean of $\alpha$ PEG Abs concentrations was calculated to be $52 \mathrm{ng} / \mathrm{mL}$ for IgG and $22 \mathrm{ng} / \mathrm{mL}$ for IgM. While race was not shown to have an effect on $\alpha$ PEG Ab levels, both serum concentration and prevalence of $\alpha \mathrm{PEG}$ IgG decreased with age, and females were more likely to have detectable $\alpha$ PEG IgM levels. Interestingly, analysis of historical samples showed a higher prevalence of $\alpha$ PEG Abs than previously reported (0.2\% in 1984) [20]. Approximately $56 \%$ of serum samples from the 1970s to 1990s presented detectable levels of $\alpha$ PEG IgG and/or IgM [21]. The high percentage of historical samples that were positive for $\alpha$ PEG Abs indicates that Richter et al. might have underestimated the prevalence of $\alpha$ PEG Abs, likely due to the use of a less sensitive detection method [21]. However, the increase in the presence of $\alpha \mathrm{PEG}$ $\mathrm{Ab}$ from $56 \%$ in historical samples to $72 \%$ in contemporary samples supports the hypothesis that $\alpha$ PEG Abs levels in the general population is increasing due to the increased prevalence of PEG in commonly used products. 


\section{aPEG Antibodies and Adverse Reactions to PEGylated Therapeutics}

Pegloticase is a recombinant uricase, PEGylated with approximately 36 chains of $10 \mathrm{kDa}$ PEG, used in the treatment of patients with refractory gout [26]. In the 2006 open-label phase I trial of Pegloticase, Ganson et al. detected anti-PEG IgG and IgM via ELISA in 5 out of $13(38 \%)$ patients after a single subcutaneous injection of the drug [43]. However, it should be noted that the ELISA was performed using a wash buffer containing $0.1 \%$ Tween-20, a polyoxyethylene surfactant that can have cross-reactivity with and alter the detection of $\alpha$ PEG Abs [43].

Eight years later, Hershfield et al. investigated the efficacy of a less frequent dosing regimen of Pegloticase, as well as the presence of pre-existing and treatment-induced $\alpha \mathrm{PEG} A b$ levels in a phase 2 clinical trial [26]. Of the 30 participants, 13 (43\%) developed $\alpha$ PEG Abs that led to accelerated drug clearance, relative to pharmacokinetics observed for patients without detectable Abs [26]. The percentage of patients who developed $\alpha \mathrm{PEG} \mathrm{Ab}$ is comparable to the $38 \%$ positive rate Ganson et al. had found in 2006 [43]. In addition to the ELISA developed by Ganson et al., Hershfield et al. implemented a competition ELISA to determine the specificity of $\alpha$ PEG Abs [26]. Samples were incubated with either phosphate-buffered saline, $10 \mathrm{kDa}$ PEG-diol (PEG without the methoxy terminal), or unmodified recombinant uricase [26]. Incubation with $10 \mathrm{kDa}$ PEG-diol, but not with the non-PEGylated uricase, caused inhibition in the $\alpha$ PEG Ab ELISA in all $13 \alpha$ PEG $\mathrm{Ab}$ positive samples post-treatment [26]. It was therefore concluded that the Abs recognized the PEG backbone, rather than the methoxy or the unmodified protein [26]. In addition to treatment-induced Abs, Hershfield et al. detected preexisting $\alpha$ PEG Abs in 19\% of Pegloticase-naive patients, all of which were classified as non- or transient responders to the drug treatment [26]. Given the correlation established between higher $\alpha$ PEG Ab levels and decreased therapeutic efficacy, screening patients for pre-existing $\alpha \mathrm{PEG}$ Abs prior to the administration of PEGylated drugs can help to determine the probability of therapeutic success.

Pegnivacogin is an RNA aptamer that inhibits coagulation factor IXa, PEGylated with $40 \mathrm{kDa}$ branched methoxy polyethylene glycol (mPEG) [27]. A 2013 phase 2b clinical trial of the drug assessed the safety, efficacy, and pharmacokinetics of an anticoagulation system containing Pegnivacogin in patients with acute coronary syndrome [27]. Minutes after the administration of the first dose, two patients developed an anaphylactic reaction, and one developed an isolated skin reaction [27]. This caused the trial, involving 640 patients, to be terminated [23]. The 3 patients that developed severe allergic reactions to the treatment with Pegnivacogin had the highest blood concentrations of pre-existing $\alpha$ PEG IgG among all study participants (within the top $2.3 \%$ ). In total, $36 \%$ of patients had positive titers of $\alpha$ PEG IgG. A competition ELISA showed that the Abs present in these samples were specific to Pegloticase, Pegnivacogin, Adagen ${ }^{\circledR}, 10$ kDa PEG-diol, $10 \mathrm{kDa} \mathrm{mPEG}$, and a hexylamino 40-kDa branched mPEG. Of note, the Abs did not bind to the un-PEGylated adapter, demonstrating the antibody's specificity to the PEG component of the drug. Serum samples from trial patients were tested using two ELISAs, one detecting IgG specific to the $40 \mathrm{kDa}$ mPEG chains attached to Pegnivacogin, and the other IgG specific to Pegloticase. Similarly to the ELISA developed by Hershfield et al., the assay was not quantitative [26]. The ELISAs read an absorbance relative to the $\alpha$ PEG Ab concentration of each sample, but without converting absorbance values to the actual $\alpha \mathrm{PEG} \mathrm{Ab}$ concentration through a standard curve, it is not possible to compare $\alpha \mathrm{PEG}$ Ab levels between different studies $[23,26]$.

Pegasparaginase, commercially known as Oncaspar $₫$, is an E. coli-produced asparaginase, PEGylated with $5 \mathrm{kDa}$ mPEG through a succinimidyl succinate linker (SS-linker) [44]. The drug is used to treat pediatric acute lymphoblastic leukemia (ALL) [44, 45]. When PEGylated, the non-human epitopes-present on the drug are less immunogenic, but in the presence of $\alpha$ PEG Abs, neutralizing hypersensitivity reactions and accelerated drug clearance have occurred, compromising the efficacy of the treatment $[46,47]$.

After treatment with Pegasparaginase, in 2007, Armstrong et al. detected $\alpha$ PEG IgM in 9 out of 28 (32\%) patients using a hemagglutination assay, and in 13 out of 28 (46\%) patients by incubating samples with PEG beads and analyzing them via flow cytometry [48]. Accelerated clearance of Pegasparaginase was linked to the presence of $\alpha \mathrm{PEG}$ IgM in the study, as all patients with positive $\alpha \mathrm{PEG}$ IgM titers exhibited low asparaginase activity. It was also reported that $13 \%$ of patients treated with unmodified asparaginase tested positive for $\alpha \mathrm{PEG}$ Abs, although the antibodies did not interfere with the asparaginase serum activity. The Abs detected in the control group are thought to be preexisting $\alpha$ PEG Abs, rather than induced by the treatment, as the control drug did not contain PEG.

In 2020, Kloos et al. investigated neutralizing hypersensitivity reactions to Pegasparaginase in different stages of treatment [49]. Patients received Pegasparaginase intravenously thrice over a 40-day induction phase. Following a 12-week interruption, patients received 14 doses of PEG-asparaginase in the intensification course [47, 50,51]. Out of 18 children, 12 developed neutralizing hypersensitivity reactions during the induction phase, and 6 during the intensification phase [49]. In both phases, all patients presented $\alpha$ PEG IgG. $\alpha$ PEG IgM was detected in $75 \%$ of patients with hypersensitivity reaction during the induction phase, and in $50 \%$ of patients with the reaction during the intensification phase. In both groups, IgG titers were approximately 100 times higher than IgM titers. While both anti-asparaginase and anti-SSlinker antibodies have been detected, $39 \%$ of patients with 
hypersensitivity reactions had exclusively $\alpha$ PEG Abs, indicating their capacity to provoke neutralizing reactions. The authors also observed pre-existing $\alpha$ PEG IgG and IgM in 58\% and $21 \%$, respectively, of patients with no adverse reactions to the treatment. Similar to observations made by Armstrong et al., pre-existing $\alpha$ PEG Abs did not have the same capacity to provoke neutralizing reactions as $\alpha \mathrm{PEG}$ Abs acquired from treatment $[48,49]$.

\section{aPEG Antibodies and Adverse Reactions to PEGylated Liposomes}

PEGylated liposomes can be employed as drug carriers, with the benefits of altered pharmacokinetics and reduced drug toxicity [52]. However, liposomes, as opposed to proteins, peptides, and enzymes, are known to act as potent adjuvants and can induce antibody responses against otherwise weakly immunogenic antigens [53-55]. In the early 2000s, it was observed that $\alpha$ PEG IgG caused accelerated clearance after multiple injections of PEGylated liposomes [56-58]. Sroda et al. injected rabbits intravenously with liposomes containing $20 \%$ of the PEG derivative of phosphatidylethanolamine (PE) (PEG-PE) weekly, for 6 weeks [59]. The authors identified $\alpha \mathrm{PEG}$ IgG in treated animals. In a 2005 study, Semple et al. detected liposome-reactive IgM one week after the first injection of PEGylated liposomes, with titer levels increasing over the course of four injections [60]. Minimal IgM levels were observed in the plasma of mice injected with a PEG-free lipid, indicating the specificity of this antibody to PEG. It should be noted that $0.1 \%$ Tween was used in the detection ELISA [60]. Cross-reactivity between Tween, which contains multiple PEG blocks within its structure, and $\alpha \mathrm{PEG}$ Abs may have altered results.

Doxil®, the PEGylated liposomal formulation of doxorubicin, was the first FDA-approved nano-drug, coming to the market in 1995 [52, 61]. The drug is currently used in the treatment of ovarian cancer, Kaposi's sarcoma, and melanoma [52], and has been shown to induce $\alpha$ PEG Abs [25, 62]. Approximately $10 \%$ of patients treated with Doxil® experienced acute infusion-related reactions that result in termination of treatment [61]. Complement activation-related pseudo allergy (CARPA) has been found to be a major cause of these reactions [63-65]. Neun et al. investigated the role of $\alpha$ PEG Abs in CARPA in vitro [62]. Well-characterized mouse $\alpha \mathrm{PEG} \operatorname{IgG}$ and IgM clones from commercial suppliers at a concentration of 10 $\mu \mathrm{g} / \mathrm{ml}$ were incubated with Doxil®. A two-fold increase in complement component $\mathrm{C} 3 \mathrm{a}$ plasma levels was observed after the drug was incubated with a PEG backbone specific IgG clone. Additionally, all three of the assessed PEG backbone specific IgM Abs resulted in a more than a three-fold increase in C3a levels after incubation with Doxil®.

Kozma et al. assessed the time course of $\alpha$ PEG Ab Abs titers CARPA pig model [40]. Animals were immunized with
PEGylated liposomes, which induced high titers of $\alpha$ PEG IgM. Upon a bolus injection with Doxil®, a rapid decline of $\alpha$ PEG IgM titer was observed, as well as complement activation and pseudo-anaphylactic reactions in 4 out of 5 animals. The decrease in $\mathrm{Ab}$ titers can likely be attributed to scavenging of the liposome-IgM complex by the MPS.

Neun et al. also investigated the relationship between complement activation by Doxil ${ }^{\circledR}$ and pre-existing $\alpha$ PEG Abs in healthy human donors [62]. However, unlike in mice, a relationship between human $\alpha$ PEG Abs, Doxil®, and complement activation was not observed in this study. The authors hypothesized that the gap between mouse and human results occurs because mouse $\alpha \mathrm{PEG}$ Abs are monoclonal, generated by a single parent $\mathrm{B}$ cell, and recognize the same epitope on an antigen. This results in high-affinity Abs, which were used in a high concentration in the in vitro study $(10 \mu \mathrm{g} / \mathrm{ml})$. In contrast, human $\alpha$ PEG Abs are polyclonal, produced by different $\mathrm{B}$ cell clones, and can bind to different epitopes in the same antigen. Abs present in human plasma have unknown characteristics and specificity, as they were generated from environmental exposure to PEG. This supports why pre-existing $\alpha$ PEG Abs do not possess the neutralizing capacity of treatment-induced $\alpha$ PEG Abs, as observed in earlier clinical studies $[48,49]$.

In parallel work by Hsieh et al., pre-existing $\alpha$ PEG Abs were found to alter the pharmacokinetics, biodistribution, and therapeutic efficacy of Doxil® in murine models [25]. However, the animals were injected intravenously with a commercially available antibody, and had $\alpha$ PEG IgG serum concentration of approximately $15 \mu \mathrm{g} / \mathrm{mL}$, similar to the $10 \mu \mathrm{g} /$ $\mathrm{mL}$ concentration Neun et al. used when incubating mouse $\alpha$ PEG Abs with Doxil ${ }^{\circledR}$ in vitro $[25,62]$. The $\alpha$ PEG Abs concentrations used in these studies are too high compared to the $52 \mathrm{ng} / \mathrm{ml}$ mean associated with the general population determined in Yang et al., making the models clinically irrelevant for the majority of the population [21, 25].

Advances in the understanding and managing of $\alpha \mathrm{PEG}$ Abs might be important in the context of the COVID-19 pandemic. Both the Pfizer-BioNTech and Moderna SARS-CoV-2 vaccines have been recently authorized by the FDA under an Emergency Use Authorization and contain messenger ribonucleic acid (mRNA) delivered within PEGylated lipid nanoparticles. These vaccines are the first approved mRNA vaccines, and the first to include the polymer in their compositions, containing PEG with a molecular weight of $2000 \mathrm{Da}[15,16]$. Rare cases of anaphylaxis following vaccine administration have been reported by the Centers for Disease Control and Prevention (CDC) [66]. It is suspected that $\alpha \mathrm{PEG}$ Abs may be associated with anaphylactic reactions to the SARS-CoV-2 vaccine [67], and thus applying the methods outlined in this review could be helpful in avoiding and managing these reactions.

Due to global efforts to combat COVID-19, there are over 90 vaccines against SARS-Cov-2 in active clinical trials [68]. Many of them employ more traditional vaccine technology 
that does not contain PEG in their formulations. For example, the Oxford-AstraZeneca vaccine uses a chimpanzee adenovirus vector [69], while Sinovac's CoronaVac is an inactivated virus vaccine [70]. As these and many others become approved and available to the public, PEG-free vaccines might offer a viable alternative for patients with known allergy to PEG or high concentrations of $\alpha$ PEG Abs in order to avoid anaphylactic reactions.

\section{Conclusions and Future Directions}

There is a need for a standardized, sensitive, and quantitative method of $\alpha$ PEG Ab detection. Techniques, such as hemagglutination, were used for detection of $\alpha \mathrm{PEG} \mathrm{Ab}$ in early studies can only detect Abs with a strong affinity or in large concentrations in a sample, and are now outdated [19]. Because of its higher sensitivity, ELISA is currently the gold-standard method to detect $\alpha$ PEG Abs, however multiple studies used polyoxyethylene-based surfactants such as Tween in blocking and wash buffers [43, 60]. The addition of polyoxyethylene surfactants has been a target of critiques against $\alpha$ PEG Ab studies due to the ability of the surfactant to cross-react with $\alpha$ PEG Abs [71]. While today, the surfactants are no longer used in $\alpha$ PEG Abs ELISAs, most groups still develop their own detection assays [71]. This makes it difficult to compare findings between studies, especially if the concentration of the $\mathrm{Ab}$ titer is not determined. A standardized protocol for $\alpha \mathrm{PEG} \mathrm{Ab}$ detection is necessary and would accelerate the advancement of the field.

Moreover, the induction of $\alpha$ PEG Abs has been investigated mostly with strong adjuvants administered alongside high quantities of a PEGylated entity [19, 25, 58, 59]. As valuable as these studies can be in identifying the existence of $\alpha$ PEG Abs, there is no clinical relevance in the use of adjuvants to induce Abs against PEGylated therapeutics. An exception can be made in the case of PEGylated liposomes, where the nanocarrier itself can act as an adjuvant to enhance the immune response. Therefore, animal experiments that aim to induce $\alpha$ PEG Abs with therapeutic doses of PEGylated particles should be performed, considering the variety of molecular weights of PEG and polymer architectures found in FDA approved treatments. As more studies are suggesting CARPA and accelerated drug clearance could be influenced by levels of pre-existing $\alpha$ PEG Abs [25, 62], another need for animal models is to accurately reflect the concentration of $\alpha \mathrm{PEG} A b s$ found in the population. A model like this could be used to thoroughly understand how the blood concentration of $\alpha$ PEG Abs affects treatment with PEGylated therapeutics prior to a drug reaching clinical trials.

Finally, as the relation between pre-existing $\alpha$ PEG Abs and adverse reactions to PEGylated drugs is better understood, preventative methods can be implemented in the clinic. For example, a standardized ELISA could be used to screen a patient's $\alpha$ PEG Abs blood concentration prior to starting a treatment with PEGylated therapeutics. Therefore, patients with high blood concentrations of $\alpha$ PEG Abs that could potentially lead to anaphylaxis or decreased therapeutic efficacy could be directed to alternative therapeutics or receive additional monitoring in case adverse reactions occur after drug administration.

Initial misguided conclusions about the inert nature of PEG have delayed the scientific efforts to understand $\alpha$ PEG Abs [20]. Although some research groups have attempted to answer questions regarding the formation of both pre-existing and treatment-induced $\alpha \mathrm{PEG}$ Abs and reactivity with PEGylated drugs, there are still knowledge gaps yet to be explored. Recent discoveries in the structure of $\alpha$ PEG Abs revealed an open ring structure that captures and stabilizes the flexible PEG chains [72]. These findings may explain why free or crosslinked PEG chains do not elicit an $\alpha$ PEG Ab response, as the chains are not sterically presented in a way they can interact with the open ring structure on $\alpha$ PEG Abs. With the rising prevalence of PEG in consumer products and therapeutics, including novel COVID-19 vaccines, and consequently of $\alpha$ PEG Abs, these gaps must no longer be ignored.

\section{References}

1. Fruijtier-Pölloth C. Safety assessment on polyethylene glycols (PEGs) and their derivatives as used in cosmetic products. Toxicology. 2005;214(1):1-38. https://doi.org/10.1016/j.tox.2005.06.001.

2. Final report on the safety assessment of polyethylene glycols (PEGs)-6,-8,-32,-75,-150,-14M,-20M. J Am Coll Toxicol. 1993;12(5):429-57. https://doi.org/10.3109/10915819309141598.

3. Delgado C, Francis GE, Fisher D. The uses and properties of PEG-linked proteins. Crit Rev Ther Drug Carrier Syst. 1992;9(3-4):249-304.

4. Bailon P, Berthold W. Polyethylene glycol-conjugated pharmaceutical proteins. Pharm Sci Technol Today. 1998;1(8):352-6. https:// doi.org/10.1016/S1461-5347(98)00086-8.

5. Harris JM, Chess RB. Effect of pegylation on pharmaceuticals. Nat Rev Drug Discov. 2003;2(3, 3). https://doi.org/10.1038/nrd1033.

6. Veronese FM, Pasut G. PEGylation, successful approach to drug delivery. Drug Discov Today. 2005;10(21):1451-8. https://doi.org/ 10.1016/S1359-6446(05)03575-0.

7. Abuchowski A, Van Es T, Palczuk NC, Davis FF. Alteration of immunological properties of bovine serum albumin by covalent attachment of polyethylene glycol. J Biol Chem. 1977;252(11): 3578-81.

8. Harris JM, Martin NE, Modi M. Pegylation. Clin Pharmacokinet. 2001;40(7):539-51. https://doi.org/10.2165/00003088200140070-00005.

9. Bazile D, Prud'homme C, Bassoullet M, Marlard M, Spenlehauer G, Veillard M. Stealth Me. PEG-PLA nanoparticles avoid uptake by the mononuclear phagocytes system. J Pharm Sci. 1995;84(4): 493-8. https://doi.org/10.1002/jps.2600840420.

10. Deen WM, Lazzara MJ, Myers BD. Structural determinants of glomerular permeability. Am J Phys Renal Phys. 2001;281(4):F57996. https://doi.org/10.1152/ajprenal.2001.281.4.F579. 
11. Longmire M, Choyke PL, Kobayashi H. Clearance properties of nano-sized particles and molecules as imaging agents: considerations and caveats. Nanomedicine. 2008;3(5):703-17. https://doi. org/10.2217/17435889.3.5.703.

12. Hoang Thi TT, Pilkington EH, Nguyen DH, Lee JS, Park KD, Truong NP. The importance of poly(ethylene glycol) alternatives for overcoming PEG immunogenicity in drug delivery and bioconjugation. Polymers. 2020;12(2). https://doi.org/10.3390/ polym 12020298

13. Ramos-de-la-Peña AM, Aguilar O. Progress and challenges in PEGylated proteins downstream processing: a review of the last 8 years. Int J Pept Res Ther. 2020;26(1):333-48. https://doi.org/10. 1007/s10989-019-09840-4.

14. Swierczewska M, Lee KC, Lee S. What is the future of PEGylated therapies? Expert Opin Emerg Drugs. 2015;20(4):531-6. https:// doi.org/10.1517/14728214.2015.1113254.

15. Moderna COVID-19 Vaccine EUA Fact Sheet for Recipients and Caregivers. Moderna. 2020. [Online]. Available: https://www.fda. gov/media/144638/download.

16. Fact sheet for healthcare providers administering vaccine (VACCINATION PROVIDERS). Pfizer Inc., Revised, 2020. [Online]. Available: http://labeling.pfizer.com/ShowLabeling. aspx?id=14471.

17. Jang H-J, Shin CY, Kim K-B. Safety evaluation of polyethylene glycol (PEG) compounds for cosmetic use. Toxicol Res. 2015;31(2):105-36. https://doi.org/10.5487/TR.2015.31.2.105.

18. Nikitakis JM, Rieger MM, Hewitt GT, T. and F. A. Cosmetic. CTFA cosmetic ingredient handbook. Washington, D.C: Cosmetic, Toiletry, and Fragrance Association; 1988.

19. Richter AW, Åkerblom E. Antibodies against polyethylene glycol produced in animals by immunization with monomethoxy polyethylene glycol modified proteins. Int Arch Allergy Immunol. 1983;70(2):124-31. https://doi.org/10.1159/000233309.

20. Richter AW, Åkerblom E. Polyethylene glycol reactive antibodies in man: titer distribution in allergic patients treated with monomethoxy polyethylene glycol modified allergens or placebo, and in healthy blood donors. Int Arch Allergy Immunol. 1984;74(1):36-9. https://doi.org/10.1159/000233512.

21. Yang Q, Jacobs TM, McCallen JD, Moore DT, Huckaby JT, Edelstein JN, et al. Analysis of pre-existing IgG and IgM antibodies against polyethylene glycol (PEG) in the general population. Anal Chem. 2016;88(23):11804-12. https://doi.org/10.1021/acs. analchem.6b03437.

22. Bandilla KK, McDuffie FC, Gleich GJ. Immunoglobulin classes of antibodies produced in the primary and secondary responses in man. Clin Exp Immunol. 1969;5(6):627-41.

23. Ganson NJ, et al. Pre-existing anti-polyethylene glycol antibody linked to first-exposure allergic reactions to pegnivacogin, a PEGylated RNA aptamer. J Allergy Clin Immunol. 2016;137(5): 1610-1613.e7. https://doi.org/10.1016/j.jaci.2015.10.034.

24. Zhao Y, et al. Repeated injection of PEGylated solid lipid nanoparticles induces accelerated blood clearance in mice and beagles. Int $\mathrm{J}$ Nanomedicine. 2012;7:2891-900. https://doi.org/10.2147/IJN. S30943.

25. Hsieh Y-C, Wang HE, Lin WW, Roffler SR, Cheng TC, Su YC, et al. Pre-existing anti-polyethylene glycol antibody reduces the therapeutic efficacy and pharmacokinetics of PEGylated liposomes. Theranostics. 2018;8(11):3164-75. https://doi.org/10.7150/thno. 22164.

26. Hershfield MS, Ganson NJ, Kelly SJ, Scarlett EL, Jaggers DA, Sundy JS. Induced and pre-existing anti-polyethylene glycol antibody in a trial of every 3-week dosing of pegloticase for refractory gout, including in organ transplant recipients. Arthritis Res Ther. 2014;16(2):R63. https://doi.org/10.1186/ar4500.

27. Povsic TJ, Vavalle JP, Aberle LH, Kasprzak JD, Cohen MG, Mehran R, et al. A Phase 2, randomized, partially blinded, active- controlled study assessing the efficacy and safety of variable anticoagulation reversal using the REG1 system in patients with acute coronary syndromes: results of the RADAR trial. Eur Heart J. 2013;34(31):2481-9. https://doi.org/10.1093/eurheartj/ehs232.

28. Fogel DB. Factors associated with clinical trials that fail and opportunities for improving the likelihood of success: a review. Contemp Clin Trials Commun. 2018;11:156-64. https://doi.org/10.1016/j. conctc.2018.08.001.

29. Mima Y, Hashimoto Y, Shimizu T, Kiwada H, Ishida T. Anti-PEG IgM is a major contributor to the accelerated blood clearance of polyethylene glycol-conjugated protein. Mol Pharm. 2015;12(7): 2429-35. https://doi.org/10.1021/acs.molpharmaceut.5b00144.

30. Ichihara M, Shimizu T, Imoto A, Hashiguchi Y, Uehara Y, Ishida $\mathrm{T}$, et al. Anti-PEG IgM response against PEGylated liposomes in mice and rats. Pharmaceutics. 2010;3(1):1-11. https://doi.org/10. 3390/pharmaceutics3010001.

31. Shimizu T, Mima Y, Hashimoto Y, Ukawa M, Ando H, Kiwada H, et al. Anti-PEG IgM and complement system are required for the association of second doses of PEGylated liposomes with splenic marginal zone B cells. Immunobiology. 2015;220(10):1151-60. https://doi.org/10.1016/j.imbio.2015.06.005.

32. Ishida T, Wang X, Shimizu T, Nawata K, Kiwada H. PEGylated liposomes elicit an anti-PEG IgM response in a T cell-independent manner. J Control Release. 2007;122(3):349-55. https://doi.org/10. 1016/j.jconrel.2007.05.015

33. Abu Lila AS, Ichihara M, Shimizu T, Ishida T, Kiwada H. Ex-vivo/ in-vitro anti-polyethylene glycol (PEG) immunoglobulin M production from murine splenic B cells stimulated by PEGylated liposome. Biol Pharm Bull. 2013;36(11):1842-8. https://doi.org/10. 1248/bpb.b13-00562.

34. Sherman MR, Williams LD, Sobczyk MA, Michaels SJ, Saifer MGP. Role of the methoxy group in immune responses to mPEG-protein conjugates. Bioconjug Chem. 2012;23(3):485-99. https://doi.org/10.1021/bc200551b.

35. Ishida T, Ichihara M, Wang X, Kiwada H. Spleen plays an important role in the induction of accelerated blood clearance of PEGylated liposomes. J Control Release. 2006;115(3):243-50. https://doi.org/10.1016/j.jconrel.2006.08.001.

36. Saifer MGP, Williams LD, Sobczyk MA, Michaels SJ, Sherman MR. Selectivity of binding of PEGs and PEG-like oligomers to anti-PEG antibodies induced by methoxyPEG-proteins. Mol Immunol. 2014;57(2):236-46. https://doi.org/10.1016/j.molimm. 2013.07.014.

37. Sundy JS, Ganson NJ, Kelly SJ, Scarlett EL, Rehrig CD, Huang W, et al. Pharmacokinetics and pharmacodynamics of intravenous PEGylated recombinant mammalian urate oxidase in patients with refractory gout. Arthritis Rheum. 2007;56(3):1021-8. https://doi. org/10.1002/art.22403.

38. Li X, et al. Molecular insights for the biological interactions between polyethylene glycol and cells. Biomaterials. 2017;147:1-13. https://doi.org/10.1016/j.biomaterials.2017.09.002.

39. Defrance T, Taillardet M, Genestier L. T cell-independent B cell memory. Curr Opin Immunol. 2011;23(3):330-6. https://doi.org/ 10.1016/j.coi.2011.03.004.

40. Kozma GT, Mészáros T, Vashegyi I, Fülöp T, Örfi E, Dézsi L, et al. Pseudo-anaphylaxis to polyethylene glycol (PEG)-coated liposomes: roles of anti-PEG IgM and complement activation in a porcine model of human infusion reactions. ACS Nano. 2019;13(8): 9315-24. https://doi.org/10.1021/acsnano.9b03942.

41. Elsadek NE, Emam SE, Abu Lila AS, Shimizu T, Ando H, Ishima Y, et al. Pegfilgrastim (PEG-G-CSF) Induces anti-polyethylene glycol (PEG) IgM via a T cell-dependent mechanism. Biol Pharm Bull. 2020;43(9):1393-7. https://doi.org/10.1248/bpb.b20-00345.

42. Karl S, Ring J. Pro and contra of specific hyposensitization. Eur J Dermatol. 1999;9(4):325-31. 
43. Ganson NJ, Kelly SJ, Scarlett E, Sundy JS, Hershfield MS. Control of hyperuricemia in subjects with refractory gout, and induction of antibody against poly(ethylene glycol) (PEG), in a phase I trial of subcutaneous PEGylated urate oxidase. Arthritis Res Ther. 2006;8(1):R12. https://doi.org/10.1186/ar1861.

44. Müller HJ, Boos J. Use of L-asparaginase in childhood ALL. Crit Rev Oncol Hematol. 1998;28(2):97-113. https://doi.org/10.1016/ s1040-8428(98)00015-8.

45. Amylon MD, Shuster J, Pullen J, Berard C, Link MP, Wharam M, et al. Intensive high-dose asparaginase consolidation improves survival for pediatric patients with T cell acute lymphoblastic leukemia and advanced stage lymphoblastic lymphoma: a Pediatric Oncology Group study. Leukemia. 1999;13(3):335-42. https:// doi.org/10.1038/sj.leu.2401310.

46. Henriksen LT, Harila-Saari A, Ruud E, Abrahamsson J, Pruunsild $\mathrm{K}$, Vaitkeviciene G, et al. PEG-asparaginase allergy in children with acute lymphoblastic leukemia in the NOPHO ALL2008 protocol. Pediatr Blood Cancer. 2015;62(3):427-33. https://doi.org/10. $1002 / p b c .25319$.

47. Tong WH, Pieters R, Kaspers GJL, te Loo DMWM, Bierings MB, van den Bos C, et al. A prospective study on drug monitoring of PEGasparaginase and Erwinia asparaginase and asparaginase antibodies in pediatric acute lymphoblastic leukemia. Blood. 2014;123(13): 2026-33. https://doi.org/10.1182/blood-2013-10-534347.

48. Armstrong JK, Hempel G, Koling S, Chan LS, Fisher T, Meiselman $\mathrm{HJ}$, et al. Antibody against poly(ethylene glycol) adversely affects PEG-asparaginase therapy in acute lymphoblastic leukemia patients. Cancer. 2007;110(1):103-11. https://doi.org/10.1002/cncr. 22739 .

49. Kloos R, van der Sluis IM, Mastrobattista E, Hennink W, Pieters R, Verhoef J-J. Acute lymphoblastic leukaemia patients treated with PEGasparaginase develop antibodies to PEG and the succinate linker. Br J Haematol. 2020;189(3):442-51. https://doi.org/10.1111/ bjh. 16254 .

50. Silverman LB, Gelber RD, Dalton VK, Asselin BL, Barr RD, Clavell LA, et al. Improved outcome for children with acute lymphoblastic leukemia: results of Dana-Farber Consortium Protocol 91-01. Blood. 2001;97(5):1211-8. https://doi.org/10.1182/blood. v97.5.1211.

51. van der Sluis IM, et al. Efficacy and safety of recombinant E. coli asparaginase in children with previously untreated acute lymphoblastic leukemia: a randomized multicenter study of the Dutch Childhood Oncology Group. Pediatr Blood Cancer. 2018;65(8): e27083. https://doi.org/10.1002/pbc.27083.

52. Barenholz Y. Doxil®-the first FDA-approved nano-drug: lessons learned. J Control Release. 2012;160(2):117-34. https://doi.org/10. 1016/j.jconrel.2012.03.020.

53. O'Hagan DT, Singh M. Microparticles as vaccine adjuvants and delivery systems. Expert Rev Vaccines. 2003;2(2):269-83. https:// doi.org/10.1586/14760584.2.2.269.

54. Boeckler C, Dautel D, Schelté P, Frisch B, Wachsmann D, Klein $\mathrm{JP}$, et al. Design of highly immunogenic liposomal constructs combining structurally independent $\mathrm{B}$ cell and $\mathrm{T}$ helper cell peptide epitopes. Eur J Immunol. 1999;29(7):2297-308. https://doi.org/ 10.1002/(SICI) 1521-4141(199907)29:07<2297::AIDIMMU2297>3.0.CO;2-5.

55. Li WM, Bally MB, Schutze-Redelmeier MP. Enhanced immune response to T-independent antigen by using $\mathrm{CpG}$ oligodeoxynucleotides encapsulated in liposomes. Vaccine. 2001;20(1-2):148-57. https://doi. org/10.1016/s0264-410x(01)00277-8.

56. Dams ETM, et al. Accelerated blood clearance and altered biodistribution of repeated injections of sterically stabilized liposomes. J Pharmacol Exp Ther. 2000;292(3):1071-9.
57. Ishida T, Masuda K, Ichikawa T, Ichihara M, Irimura K, Kiwada H. Accelerated clearance of a second injection of PEGylated liposomes in mice. Int J Pharm. 2003;255(1):167-74. https://doi.org/ 10.1016/S0378-5173(03)00085-1.

58. Judge A, McClintock K, Phelps JR, MacLachlan I. Hypersensitivity and loss of disease site targeting caused by antibody responses to PEGylated liposomes. Mol Ther. 2006;13(2): 328-37. https://doi.org/10.1016/j.ymthe.2005.09.014.

59. Sroda K, Rydlewski J, Langner M, Kozubek A, Grzybek M, Sikorski AF. Repeated injections of PEG-PE liposomes generate anti-PEG antibodies. Cell Mol Biol Lett. 2005;10(1):37-47.

60. Semple SC, Harasym TO, Clow KA, Ansell SM, Klimuk SK, Hope MJ. Immunogenicity and rapid blood clearance of liposomes containing polyethylene glycol-lipid conjugates and nucleic acid. J Pharmacol Exp Ther. 2005;312(3):1020-6. https://doi.org/10. 1124/jpet.104.078113.

61. Doxil Package Insert. Baxter Healthcare Corporation. 2019. [Online]. Available: doxil.com.

62. Neun B, Barenholz Y, Szebeni J, Dobrovolskaia M. Understanding the role of anti-PEG antibodies in the complement activation by doxil in vitro. Molecules. 2018;23(7):1700. https://doi.org/10. 3390/molecules 23071700 .

63. Szebeni J. The interaction of liposomes with the complement system. Crit Rev Ther Drug Carrier Syst. 1998;15(1). https://doi.org/ 10.1615/CritRevTherDrugCarrierSyst.v15.i1.20.

64. Chanan-Khan A, Szebeni J, Savay S, Liebes L, Rafique NM, Alving CR, et al. Complement activation following first exposure to pegylated liposomal doxorubicin (Doxil@): possible role in hypersensitivity reactions. Ann Oncol. 2003;14(9):1430-7. https:// doi.org/10.1093/annonc/mdg374.

65. Szebeni J. Complement activation-related pseudoallergy: a new class of drug-induced acute immune toxicity. Toxicology. 2005;216(2):106-21. https://doi.org/10.1016/j.tox.2005.07.023.

66. ACIP December 19 and 20, 2020 Presentation Slides | Immunization Practices | CDC. 2020. https://www.cdc.gov/ vaccines/acip/meetings/slides-2020-12-19-20.html. Accessed Dec. 26, 2020.

67. de Vrieze J. Dec. 21, 2020, and 5:10 Pm, Suspicions grow that nanoparticles in Pfizer's COVID-19 vaccine trigger rare allergic reactions. Science | AAAS. 2020. https://www.sciencemag.org/ news/2020/12/suspicions-grow-nanoparticles-pfizer-s-covid-19vaccine-trigger-rare-allergic-reactions. Accessed Dec. 26, 2020.

68. Zimmer C, Corum J, Wee S-L. Coronavirus vaccine tracker. The New York Times. 2020.

69. Knoll MD, Wonodi C. Oxford-AstraZeneca COVID-19 vaccine efficacy. Lancet. 2020;0(0). https://doi.org/10.1016/S01406736(20)32623-4.

70. Zhang Y, et al. Safety, tolerability, and immunogenicity of an inactivated SARS-CoV-2 vaccine in healthy adults aged 18-59 years: a randomised, double-blind, placebo-controlled, phase $1 / 2$ clinical trial. Lancet Infect Dis. 2020;0(0). https://doi.org/10.1016/ S1473-3099(20)30843-4.

71. Schellekens H, Hennink WE, Brinks V. The immunogenicity of polyethylene glycol: facts and fiction. Pharm Res. 2013;30(7): 1729-34. https://doi.org/10.1007/s11095-013-1067-7.

72. Huckaby JT, et al. Structure of an anti-PEG antibody reveals an open ring that captures highly flexible PEG polymers. Commun Chem. 2020;3(1):1. https://doi.org/10.1038/s42004-020-00369-y.

Publisher's Note Springer Nature remains neutral with regard to jurisdictional claims in published maps and institutional affiliations. 